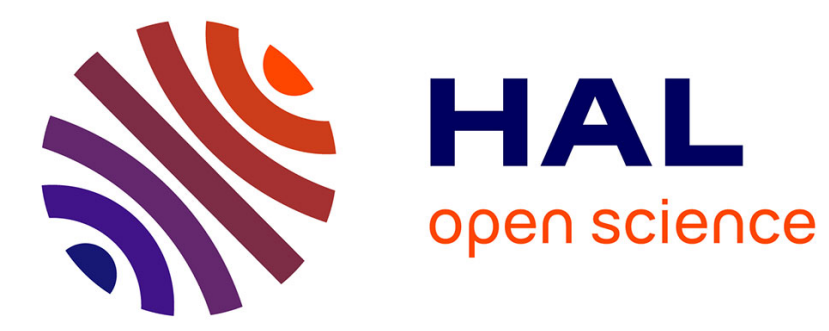

\title{
Development and Application of Micromechanical Material Models for the Characterization of Materials
}

\author{
D. Sun, M. Sester, W. Schmitt
}

\section{To cite this version:}

D. Sun, M. Sester, W. Schmitt. Development and Application of Micromechanical Material Models for the Characterization of Materials. Journal de Physique IV Proceedings, 1996, 06 (C6), pp.C6-431C6-439. 10.1051/.jp4:1996643 . jpa-00254476

\section{HAL Id: jpa-00254476 https://hal.science/jpa-00254476}

Submitted on 1 Jan 1996

HAL is a multi-disciplinary open access archive for the deposit and dissemination of scientific research documents, whether they are published or not. The documents may come from teaching and research institutions in France or abroad, or from public or private research centers.
L'archive ouverte pluridisciplinaire HAL, est destinée au dépôt et à la diffusion de documents scientifiques de niveau recherche, publiés ou non, émanant des établissements d'enseignement et de recherche français ou étrangers, des laboratoires publics ou privés. 


\title{
Development and Application of Micromechanical Material Models for the Characterization of Materials
}

D.Z. Sun, M. Sester and W. Schmitt

Fraunhofer Institut Werkstoffmechanik, Wöhlerstrasse 11, 79108 Freiburg, Germany

\begin{abstract}
The concept of the local approach is applied to investigate different damage mechanisms of structural steels by micromechanical material models. Static and dynamic fracture resistance curves for a neutron-embrittled weld material are derived from tensile and Charpy-type specimens with the modified Gurson model. The behaviour of a test piece with a crack in the ferritic base material beneath an austenitic cladding could well be predicted. A constitutive model for creep and creep rupture was developed, implemented in a finite element program and applied to tests on a $12 \% \mathrm{Cr}$ steel. The model is a combination of the viscoplastic Robinson model and a damage mechanics model. It is formulated with internal variables for isotropic and kinematic hardening and with a scalar damage parameter. The application of the model to modified $\mathrm{C}(\mathrm{T})$ specimens with different hole diameters shows a good agreement between the predictions and the experiments.
\end{abstract}

\section{INTRODUCTION}

Standard constitutive equations in continuum mechanics establish the macroscopic relation between deformation and stress tensors in a phenomenological way. Advanced micromechanical models are constitutive equations including internal variables which describe the development of the microstructure, like, e.g., the decreasing porosity in a sintering material or the increasing damage on grain boundaries by microcracks for materials exhibiting a particular kind of creep damage. The application of those models in finite element analyses of specimens and structures requires spatial discretization in microstructural dimensions and has thus become feasible only in recent years when powerful computers became available. Since micromechanical models are based on the physical description of microscopical mechanisms of these phenomena, the application of the local approach is not limited to certain loading conditions and geometries of specimens or components.

Together with elaborate experimental techniques micromechanical damage models enable the determination of ductile and creep fracture toughness from simple specimens requiring only small material volumes. For neutron-embrittled weld materials, e.g., ductile fracture resistance curves could be derived and fracture toughness reference curves adjusted on the basis of tensile and Charpy-type tests. Those hybrid (numerical-experimental) techniques have also been developed for creep crack growth when creep cavities on grain boundaries grow by a constrained diffusion mechanism. 


\section{DUCTILE FRACTURE}

The ductile fracture model is based on a flow function derived by Gurson [1] and modified by Needleman and Tvergaard [2]. The microscopical processes of ductile fracture characterized by nucleation, growth and coalescence of voids are included in the constitutive relations. All engineering metals and alloys contain inclusions and second-phase particles at which, in the course of plastic deformation by either debonding or cracking, microvoids nucleate and grow until void coalescence occurs by a localized internal necking of the intervoid matrix or by the formation of shear bands. In this model the voids are represented by a single parameter, the void volume fraction $f$. Its evolution equation consists of two terms, namely the nucleation and growth

$$
\dot{f}=\dot{f}_{\text {growth }}+\dot{f}_{\text {nucl }}
$$

The void growth rate is proportional to the plastic volume dilatation rate and depends exponentially on stress triaxiality. The nucleation rate can be described by using strain or stress criterion. Plastic flow in porous materials does not only depend on the effective plastic strain, $\varepsilon^{p}$, in the matrix material but, according to this model, also on a second internal variable, the void volume fraction, $f$. The original assumption that the microvoids do not interact is not justified for modelling the final stage of void growth when coalescence of voids by localized internal necking of the intervoid matrix occurs. Needleman and Tvergaard, e.g. [2], therefore introduced an empirical modification of Gurson's yield function

$$
\Phi\left(\sigma^{\prime}, \operatorname{tr} \sigma, f, \bar{\sigma}\right)=\frac{3 \sigma^{\prime} \cdot \sigma^{\prime}}{2 \bar{\sigma}^{2}}+2 q f^{*} \cosh \left(\frac{\operatorname{tr} \sigma}{2 \bar{\sigma}}\right)-1-\left(q f^{*}\right)^{2}=0
$$

$\sigma$ and $\sigma^{\prime}$ are the (mesoscopic) Cauchy stress tensor and its deviator, respectively. $\sigma\left(\varepsilon^{p}\right)$ is the actual flow stress of the matrix material. The parameter $q$ holds for an earlier loss of the stress carrying capability of the material as in Gurson's original yield function and the modified void volume fraction $f^{*}$ is introduced accounting for the coalescence of voids which occurs after a critical void volume fraction $f_{c}$ is reached. Eqn. (2) reduces to the original von Mises yield function if no voids are present, i.e., $f^{*}=0$.

\subsection{Determination of Material Parameters}

Two classes of material parameters are needed: parameters which characterize the hardening of the material in the classical rate independent plasticity or in visco-plasticity, and parameters which characterize the evolution of damage in the modified Gurson model. These include seven parameters in total, three of them model void nucleation and four describe the evolution of void growth up to coalescence and final failure. The most important of these parameters is $f_{c}$, which, however is not independent on the choice of the other parameters. By simulating the ductile fracture of a round tensile bar with the Gurson model it was found that the onset of macroscopic fracture is associated with a sharp kink in the load deformation curve [2,3]. Fitting the numerical results to the experimental data at this point has therefore become a common technique to determine $f_{c}$, which turned out to be nearly independent of the triaxiality. Figure 1 shows for static and dynamic loading the measured and calculated load vs. diameter change curves of smooth tensile specimens from the pressure vessel steel $22 \mathrm{NiMoCr} 37 \approx$ ASTM A $508 \mathrm{Cl} 2$ 2). The critical void fraction $f_{c}=0.045$ was determined by fitting the sudden drop in the numerical load vs. displacement curve of the static tensile test with the measured displacement at rupture. The fracture behaviour of the dynamic tests was well predicted by using the same set of micromechanical parameters. Strain-rate hardening and adiabatic softening are two important phenomena in dynamic tests and have been taken into account in the modified Gurson model [4]. 


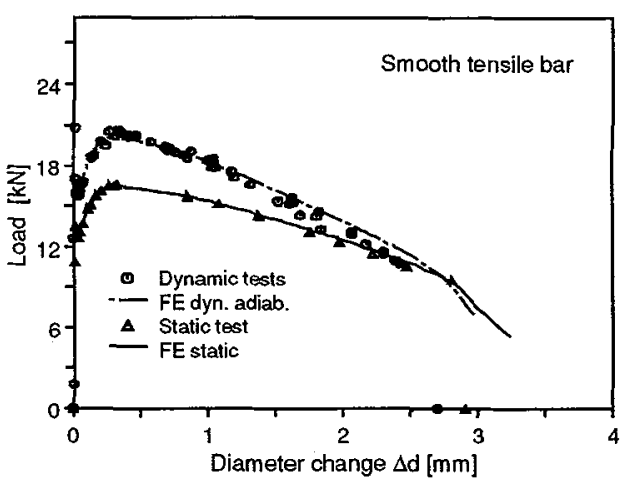

Fig. 1: Measured and calculated load vs. displacement curves of smooth tensile bars under static and dynamic loading.

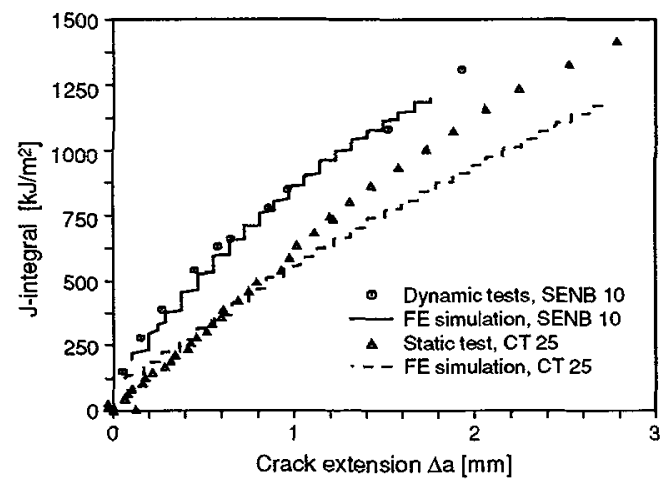

Fig. 2: Measured and calculated $\mathbf{J}_{\mathrm{R}}$-curves for static and dynamic loading.

A second important material parameter in the application to cracked structures is the characteristic distance $l_{c}$, over which $f_{c}$ must be exceeded in order to initiate or propagate the crack. The characteristic length $l_{c}$ is closely related to the microstructure (inclusion spacing). There are different methods for introduction of the $l_{c}$-value into micromechanical modeling $[5,6]$. A simple but practical method is based on the selection of a particular mesh size at the crack tip which can be obtained by matching the calculated load vs. displacement curve with the experimental one of a cracked specimen. The pair $f_{c}$ and $l_{c}$ can be considered material constants which allow the transfer from the simple specimens to complex components $[7,8]$.

A major advantage of micromechanical models is that initiation and propagation of the crack occur naturally, that is, without using additional numerical technique. The crack extension $\Delta$ a calculated by the Gurson model is identified with the size of the damage zone where due to the void growth the stresses have dropped to zero. To relate the micromechanical model to macroscopic fracture-mechanics concepts, the J-resistance curves can be evaluated from the numerical results. Figure 2 shows the calculated and measured $\mathrm{J}_{\mathrm{R}}$-curves for static and dynamic loading. Considering the scatter of the material strength, the agreement between the simulation and the experiment is very good. It should be emphasized that the same set of micromechanical parameters was used for the simulations of the different specimen geometries and loading rates [4]. In opposition to the parameters for the micromechanical model the $J_{R}$-curve is dependent on specimen geometry and loading rate.

\subsection{Evaluation of Fracture Toughness from Small specimens}

The Gurson model was applied to assess the toughness degradation of a pressure vessel weld material of a German BWR due to neutron flux [9]. The available material consisted of several broken Charpy specimens and the force-displacement records of these tests. Since stress-strain data of the irradiated situation were not available, sub-sized tensile specimens (diameter 2,6 mm) and SENB specimens $(4,9$ $\times 4,9 \times 24,5 \mathrm{~mm}^{3}$ ) were fabricated from broken halfs of Charpy specimens and tested in the hot cell facilities of SIEMENS. From the tensile specimens stress-strain curves and the critical volume fraction of voids, $f_{c}$, were determined by numerical simulations. The strain rate sensitivity of the material was obtained from the numerical simulation of the original Charpy test in comparison with the test record. From a side-grooved SENB specimen tested by SIEMENS in a $300 \mathrm{~J}$ pendulum the characteristic length, $l_{c}$, was derived, as well as a dynamic $J_{R}$-curve. With these parameters it was also possible to simulate a fictitious $\mathrm{C}(\mathrm{T})$ test and to derive a static $J_{R}$-curve. Three SENB specimens were tested with different impact energies in order to achieve different amonts of ductile crack extensions and, hence, to determine a multi-specimen dynamic resistance curve. All results are compiled in Figure 3. The computed dynamic resistance curve is well supported by the experimental data, and the static curve lies well below the 
dynamic curve. It is important to note that in all dynamic tests the fracture surfaces showed only dimples. Therefore, the initiation values of the static and dynamic $J_{R}$-curves could be converted into $K_{J_{i}}$-values and used to fit the ASME- $K_{l c}$ curve with a reference temperature of $56^{\circ} \mathrm{C}$ as a conservative envelope of the real $K_{l c}$ curve of the irradiated weld material [9].

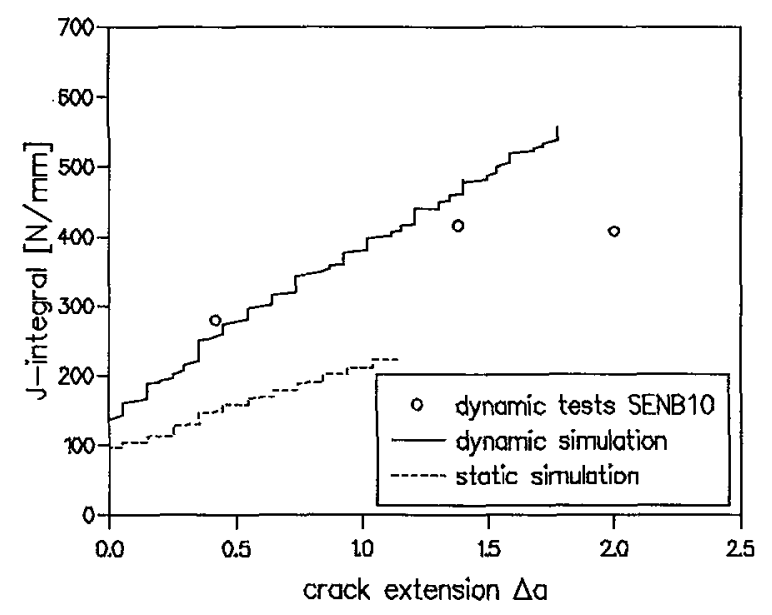

Fig. 3: Static and dynamic J resistance curves of irradiated weld material.

\subsection{Safety Analysis of a Test Piece Containing a Subclad Crack}

The criticality of hypothetical cracks located in the ferritic base material beneath the austenitic cladding ist strongly influenced by the integrity of the cladding. The proper assessment of the load carrying capacity of the cladding is difficult since the application of the $\mathbf{J}$-integral concept requires homogeneous material and the toughness gradients in the material are difficult to determine by standard test procedures. Therefore, an experiment was performed and analyzed with a cladded specimen containing a semielliptical flaw in the ferritic base material loaded under three-point bending.

The specimen is made of the ferritic steel, German designation 20 MnMoNi 55 (ASTM A 508 Cl 3) with an austenitic cladding. Beneath the cladding a semi-elliptical surface crack $5 \mathrm{~mm}$ deep and $30 \mathrm{~mm}$ long had been fabricated in the base metal before the austenitic cladding was welded. The test was performed at room temperature where ductile material behaviour is prevailing in cladding and base material. Hence, the simulation of the test is performed on the basis of the modified Gurson model.

Figure 4 shows a sketch of the specimen and of the test set-up. Due to the influence of the heat input during the welding process there is a gradient in the material properties between the unaffected base material and the cladding (taken into account by introducing a fine grain zone and a coarse grain zone). Sub-sized round bar tension specimens were taken from another representative block in order to characterize the different material zones by stress-strain curves and critical void volume fractions for the Gurson model. The validation of the Gurson parameters is achieved by comparing the measured and calculated J-resistance curves from four SENB (10 x 10)-specimens taken from different materials zones. From these tests and the corresponding numerical simulations the appropriate element sizes representing the characteristic material length were obtained. 


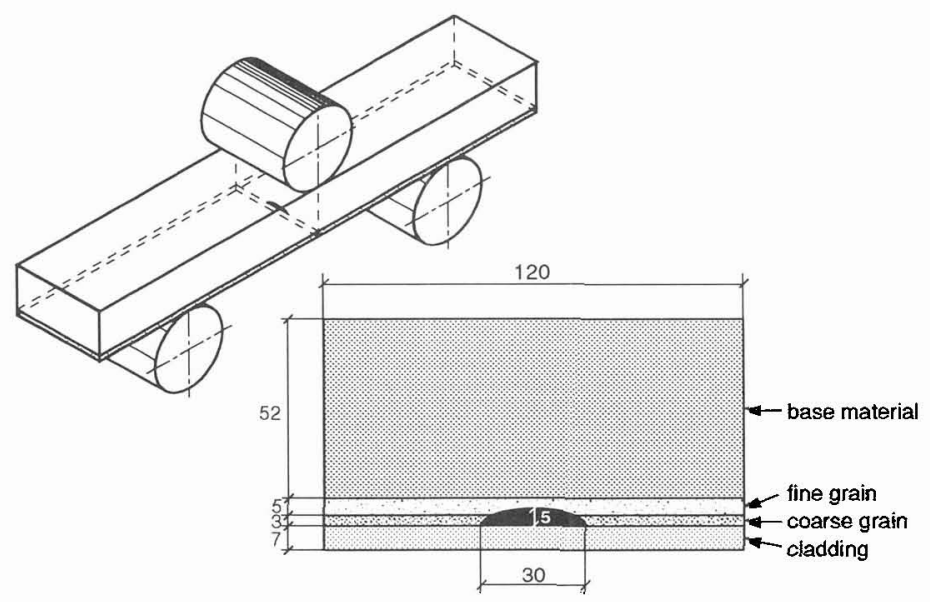

Fig. 4: Test set-up and specimen geometry.

In two-dimensional pre-test calculations the crack was modelled as a through-crack, a region around the crack was in plane strain, the rest of the specimen in plane stress. These calculations predicted initiation in the cladding at a bending displacement of $4 \mathrm{~mm}$ and in the base material at $5 \mathrm{~mm}$. In the experiment, initiation and extension were monitored by direct current potential, with probes in the cladding and in the base material, and by strain gauges attached above the crack on the cladding. After the test the numerical simulation was repeated using a reduced three-dimensional model as shown in Figure 5. Here, only a region around the crack is modelled in 3D, the remaining specimen is modelled in plane stress. The proper transition between the plane and the volumetric parts of the mesh is ensured with constraint equations.
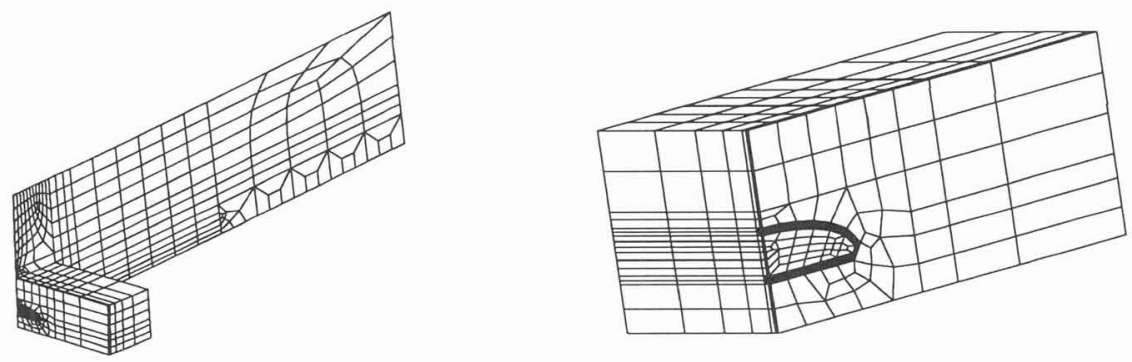

Fig. 5: Combined 2D/3D finite element model and 3D-part of the mesh containing the crack beneath the cladding in the base material.

Figure 6 shows the force vs. bending displacement diagram of the experiment together with the calculated curves. Both calculated curves are close together and give a rather good approximation to the experimental curve. However, at larger displacements crack extension especially in the cladding is overestimated by the two-dimensional simulation and the resulting force is increasingly underestimated. The threedimensional model continues to match the experimental curve very well. 


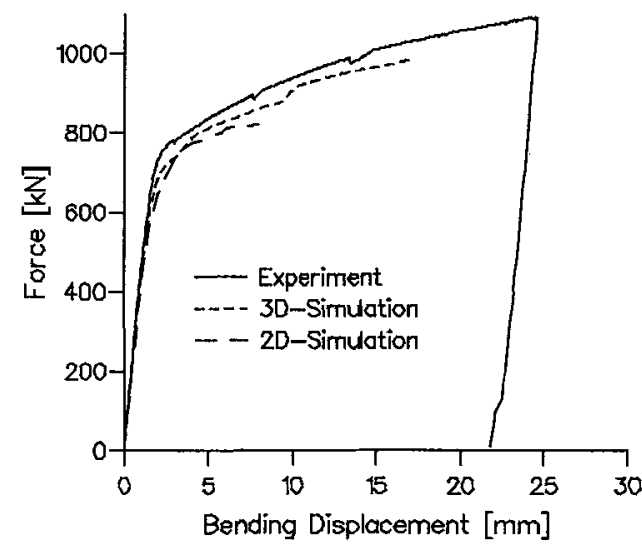

Fig. 6: Measured and calculated force vs. bending displacement.

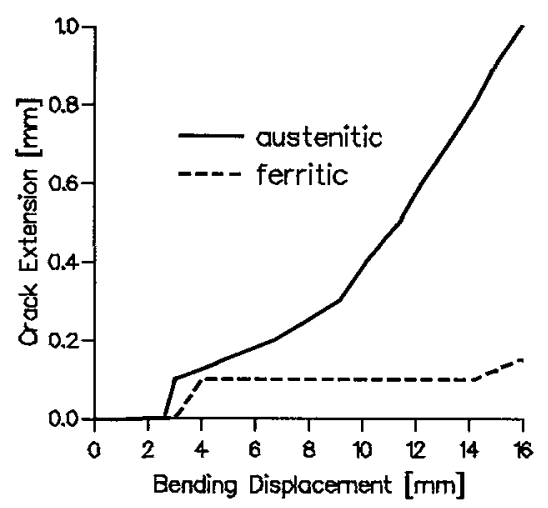

Fig. 7: Calculated ductile crack in cladding and base material.

Figure 7 shows the calculated crack extension in the cladding and in the base material, evaluated at the deepest point of the crack for the three-dimensional model. The crack propagation takes place predominantly in the cladding. This is confirmed by the evaluation of the potential drop and of the strain gauge signal above the crack.

\section{CREEP DAMAGE}

A constitutive model for creep and creep rupture was developed, implemented in a finite element program and applied to tests on a $12 \% \mathrm{Cr}$ steel. The model is a combination of the viscoplastic Robinson model [10] and a damage mechanics model. It is formulated with internal variables for isotropic and kinematic hardening and with a scalar damage parameter.

Under typical service conditions of ferritic creep-resistant steels $\left(550^{\circ} \mathrm{C}\right.$, stresses below $\left.100 \mathrm{MPa}\right)$, the lifetime is limited by the formation of cavities on grain boundaries. In the constrained limit which is relevant to our application, the diffusive growth of cavities is constrained by the creep rate of the surrounding material. As a result, macroscopic stresses are redistributed in such a way that grain boundary facets containing cavities act as traction-free microcracks.

Their effect on the macroscopic creep rate is described by Hutchinson's damage parameter, $\rho$, which is a measure of the microcrack density [11]. For larger densities, Hutchinson's linear theory was extended by Riedel [12] and Rodin and Parks [13] using the differential self consistent method.

These self-consistent estimates were checked by numerical cell model calculations. Two idealized microcrack arrangements and corresponding cell models were worked out numerically to explore the influence of a distribution of microcracks on the constitutive response of a creeping solid. The idealized solid is considered to consist of a periodic assembly of hexagonal cells or tetrakaidekahedrons (Figure 8). Every cell contains a penny-shaped microcrack in a power-law creeping material. Due to the periodic arrangement of the cells it is sufficient to simulate a representative cell by applying appropriate boundary conditions. The unit cells were analysed with the finite element method. Different microcrack densities and stress states were considered. The effect of grain boundary sliding was neglected in these cell-model calculations, as in most analytical works. The results confirmed the prediction of analytical estimates of Rodin and Parks. Hence the Rodin and Parks model was chosen to account for the effect of creep damage in the macroscopic constitutive equation. 


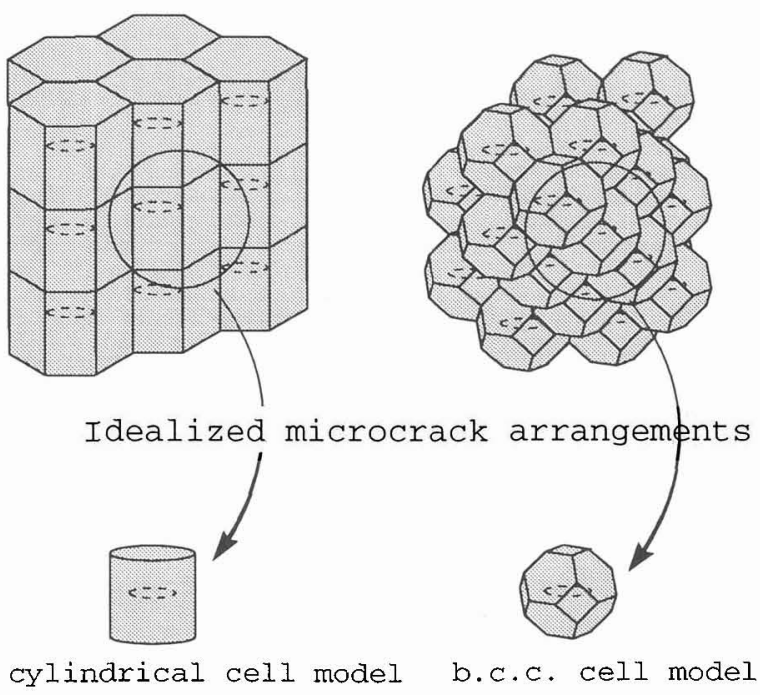

Fig. 8: Representative unit cells containing microcracks.

The model is completed by an empirical evolutionary equation for the microcrack density. In contrast to purely phenomenological damage models, the damage variable in the present micromechanical model has a clear physical meaning and may be measured with suitable methods.

In the combined Robinson and Rodin and Parks model, the inelastic strain rate tensor $\dot{\varepsilon}_{\mathrm{ij}}$ has the form:

$$
\dot{\varepsilon}_{i j}=\frac{A\left(1+\alpha Y^{2}\right)^{\frac{n-1}{2}}}{\sqrt{J_{2}\left(\Sigma_{i j}\right)}}\left(\frac{J_{2}\left(\Sigma_{i j}\right)}{K}-\left(1+\alpha Y^{2}\right)^{\frac{-(n+1)}{n}}\right)^{\frac{n}{2}}\left(\left(1+\frac{2}{3} \alpha Y\right) \Sigma_{i j}+\frac{2}{9} \alpha Y \sigma \delta_{i j}\right)
$$

This equation is valid if both $\mathrm{s}_{\mathrm{ij}} \sum_{\mathrm{ij}}>0$ and $\mathrm{J}_{2}\left(\sum_{\mathrm{ij}}\right)>\mathrm{K}\left[1+\sigma \mathrm{Y}^{2}\right]^{-(\mathrm{n}+1) / \mathrm{a}}$ hold, otherwise $\dot{\varepsilon}_{\mathrm{ij}}=0 . \mathrm{J}_{2}$ denotes the second invariant of the effective stress $\sum_{i j}$, which is defined as $\sum_{i j}=s_{i j}-a_{i j}\left(1+\alpha Y^{2}\right)^{-(n+1) / 2 n}$. The function $\alpha(n, \rho)$ describes the enhancement of the creep rate caused by grain boundary damage. The parameter $Y$ characterizes the stress state and is defined as $Y=\sigma_{m} / \sigma+2 / 3$ with the mean stress $\sigma_{m}$ and the von Mises stress $\sigma . s_{\mathrm{ij}}$ is the deviatoric part of the stress tensor $\sigma_{\mathrm{ij}}$ and $\delta_{\mathrm{ij}}$ is the Kronecker delta. The material parameters $\mathrm{A}$ and $\mathrm{n}$ can be interpreted as viscosity and creep exponent, respectively. The evolution of the state variables $a_{i j}$ (kinematic hardening) $\mathrm{K}$ (isotropic hardening) and $\rho$ (damage parameter) is given by separate evolution equations. For $\rho=0$ (no damage) the equations of the original Robinson model are recovered.

The predictive capability of the model is checked by simulations of creep experiments with compact tension $(\mathrm{C}(\mathrm{T})$ ) specimens containing either sharp cracks or drilled holes with different radii. This specimen form allows a systematic variation of the constraint in the damaged zone. The agreement between measured and calculated load line displacements is good (Figure 9), and the observed constraint effect is well reproduced by the model. 

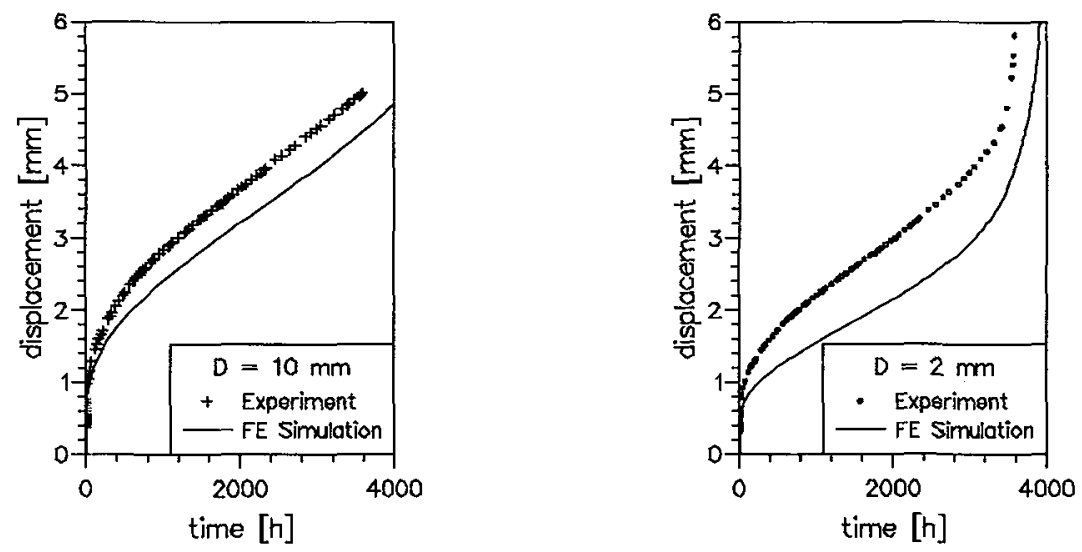

Fig. 9: Measured and calculated load line displacement for the creep tests on CT specimens with two different hole diameters.

In the simulations of creep crack growth expeiments with $C(T)$-specimens and $D E(T)$-specimens, the rate of crack growth is higher in the $C(T)$ specimens than in the $D E(T)$-specimens for the same $C^{*}$-value (Figure 10). This is in accordance with experimental findings.

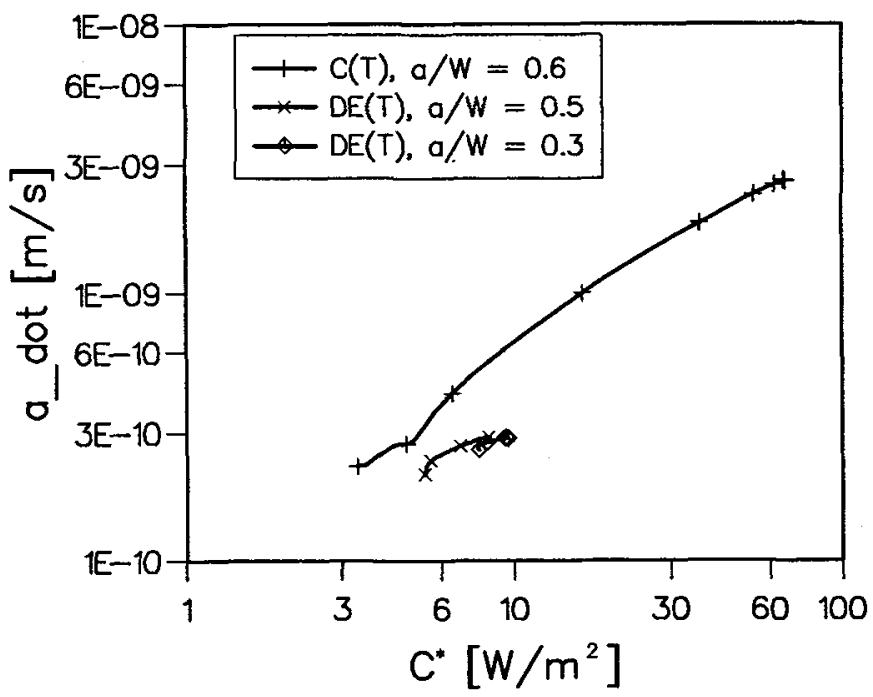

Fig. 10: Calculated crack growth rates over $C^{*}$ for different specimen geometries

\section{CONCLUSIONS}

Micromechanical models were applied to simulate ductile fracture and creep damage. The application of micromechanical models to fracture mechanics problems, generally known as "local approach", has opened new possibilities to predict fracture toughness and tearing resistance of materials. The main advantage of 
local approaches against classical fracture mechanics is evident: the parameters of the respective models are, in principle, only material and not geometry dependent. Thus, these concepts guarantee transferability from specimens to structures over a wide range of sizes and geometries.

The material model for creep damage is a combination of the Rodin and Parks model and the viscoplastic model of Robinson. It contains an evolution law for the damage parameter $\rho$. The material parameters were fitted to different creep curves. The application of the model to the modified $C(T)$ specimens with different hole diameters shows a good agreement between the predictions and the experiments.

\section{Acknowledgements}

The authors are grateful to PreussenElektra AG, Deutsche Forschungsgemeinschaft, Bundesministerium für Bildung, Wissenschaft, Forschung und Technologie for sponsoring parts of the work

\section{References}

[1] Gurson, A. L., "Continuum Theory of Ductile Rupture by Void Nucleation and Growth: Part I-Yield Criteria and Flow Rules for Porous Ductile Media," Journal of Engineering Materials and Technology, 99, 1977, pp 2-15.

[2] Needleman, A. and Tvergaard, V., "An Analysis of Ductile Rupture in Notched Bars," Journal of Mechanics and Physics of Solids, 32, 1984, pp 461-490.

[3] Sun, D.-Z., Siegele, D., Voss, B. and Schmitt, W., "Application of Local Damage Models to the Numerical Analysis of Ductile Rupture," Fatigue \& Fracture of Engineering for Materials \& Structures, 12, 1988, pp 201-212.

[4] Sun, D.-Z., Hönig, A., Böhme, W., Schmitt, W.,"Application of Micromechanical Models to the Analysis of Ductile Fracture under Dynamic Loading," Fracture Mechanics: 25th Volume, ASTM STP 1220, F. Erdogan and Ronald J. Hartranft, Eds., 1994, pp 343-357.

[5] Rousselier, G., "Ductile Fracture Models and Their Potential on Local Approach of Fracture," Nuclear Engineering and Design, 105, 1987, pp 97-111.

[6] Sun, D.-Z., Hönig, A., "Significance of the Characteristic Length for Micromechanical Modelling of Ductile Fracture," Localized Damage III, Computer-Aided Assessment and Control, M.H. Aliabadi, A. Carpinteri, S. Kalisky and D.J. Cartwright, Eds., 1994, 287-296.

[7] Sun, D.-Z., Kienzler, R., Voss, B. and Schmitt, W., "Application of Micro-mechanical Models to the Prediction of Ductile Fracture," Fracture Mechanics: Twenty-Second Symposium (Volume II), ASTM STP 1131, S. N. Atluri, J. C. Newman, Jr., I. S. Raju, and J.S. Epstein, Eds., 1992, pp 368-378.

[8] Brocks, W., Sun, D.-Z., Hönig, A., "Verification of the Transferability of Micromechanical Parameters By Cell Model Calculations With Visco-plastic Material," 4th Int. Conf. on Plasticity, Baltimore, MD, 1993, submitted for publication in Int. J. Plasticity.

[9] Schmitt, W., Sun, D.-Z, Böhme, W. \& Nagel, G., "Evaluation of Fracture Toughness Based on Results of Instrumented Charpy Tests," Int. J. Pres. Ves. \& Piping 59, 1994, 21-29.

[10] D.N. Robinson, A Unified Creep-Plasticity Model for Structural Metals at High Temperature, ORNL Report/TM-5969 (1978)

[11] J.W. Hutchinson, Acta metall. 31 (1983) 1079-1088

[12] H. Riedel, Fracture at High Temperatures, Springer Verlag, Berlin, Heidelberg, New York, 1987

[13] G.J. Rodin and D.M. Parks, J. Mech. Phys. Solids 36 (1988) 237-249 